\title{
A Critical Literature Review on Benefits Due to Passive Solar Energy System in Educational Building
}

\author{
Dr. Jayeshkumar Pitroda ${ }^{1}$, Lalakiya Biraj ${ }^{2}$, Naghera Dhiraj ${ }^{3}$, Narodiya Jay ${ }^{4}$, \\ Patel Harsh ${ }^{5}$ \\ ${ }^{1}$ Assistant Professor, Civil Engineering Dept., B.V.M. Engineering College, Vallabh Vidyanagar, \\ Gujarat, India \\ ${ }^{2345}$ Student of Final year, B.E. (Civil), B.V.M. Engineering College, Vallabh Vidyanagar, \\ Gujarat, India
}

\begin{abstract}
The present society utilizes the electrical energy for their comfort. This electrical energy is majorly obtained by burning the fossil fuels. These fuels are decreasing in a dramatic rate and it is also contributes to the pollution. Throughout the sun's daily and annual cycles, thereby the reducing the dependence of energy consuming mechanical and electrical systems of heating and cooling. Based on the analysis of data collection, Passive solar design for home helps to reduce the consumption of electrical energy by utilizing the solar energy. Passive solar design is a green concept which is aimed to utilize the maximum solar energy in the form of heat to maintain interior thermal comfort by designing windows, walls and floors of the homes to collect the solar heat from the sun in winter and reject it in the summer. This papers presents the critical literature review on benefits due to passive solar energy system in building
\end{abstract}

Keywords: Passive Solar System, PSE

\section{INTRODUCTION}

The present society utilizes the electrical energy for their comfort. This electrical energy is majorly obtained by burning the fossil fuels. These fuels are decreasing in a dramatic rate and it is also contributes to the pollution.

Passive solar design for home helps to reduce the consumption of electrical energy by utilizing the solar energy. Passive solar design is a green concept which is aimed to utilize the maximum solar energy in the form of heat to maintain interior thermal comfort.

Throughout the sun's daily and annual cycles, thereby the reducing the dependence of energy consuming mechanical and electrical systems of heating and cooling.

The windows, walls and floors of the homes are designed to collect the solar heat from the sun in winter and reject it in the summer.

\section{Literature Review Based on Passive Solar Energy System}

The following are the previous research review based on Non-Load Bearing wall based on Different Materials.

Serkanet.al (2003) concluded that the energy-efficiency design strategies by passive solar components having the additional cost of about $9 \%$ of the total building cost, it is possible to save the total annual energy used in this specific residential building by $18 \%$. It will save three types of energy need for the space conditioning and visual comfort (i. e., heating, cooling and lighting), $61 \%$ energy use reduction in heating is the maximum energy saving, lighting energy use is also decreased by $40 \%$. However, in cooling energy need, there is an increase of $34 \%$. (1)

Andreas Athienitiset. al (2008) stated that Based on the design of the houses, it is expected that homes with low and near net-zero energy use can be designed in a cost effective manner within a period of about 5 years, provided a heat pump-based system is used for heating and heat is recovered from the PV system and efficiently utilized in the house. (3) 
Tanbiruj et.al (2010) finalized that the solar energy that receive naturally by a building can be used to heat the building without special devices to capture or collect sunlight in direct gain passive solar system. Passive solar heating can be apply by using of large sun-facing windows (south-facing in the Northern Hemisphere) and building materials. A well-insulated building with such construction element can absorb the sun's energy and reduce heating bills around 50 percent. (2)

According to U.S Department of energy a special builder-friendly computer program called BuUderGWd.e has been developed to automate the calculations involved in telling out the four worksheets. The program operates like a spreadsheet: the user fills in values for the building and the computer completes the calculations. Including all table lookups, And prints out the answers. The results are the same as if you completed the worksheets manually but it is much faster more convenient and less prone to arithmetic error. Many design variations can be evaluated very quickly.

JavadSadeghsaberi et.al (2013) observed the different methods which use in passive solar energy building like direct gain, indirect gain, isolated gain etc.(5)

NajmehNajafiet.al (2013) studied the experience in conventional architecture of Shiraz, it is possible to create an environmental and sustainable architecture. (10)

Anil kumar (2013) concluded that concept of appliance of solar energy distribution through the use of a sun path diagram and the multiple ways in which this can be used for energy efficient buildings and also for evolving passive solutions possible in buildings and also provides an overview of the sun based passive solutions and design approaches possible in the case of buildings especially with reference to tropical countries.

AbdolvahidKahoorzadeh et.al (2014) shows passive solar elements like shading devices. Additional elements would keep the interior space at a more comfortable and stable temperature. Similarly, the indoor humidity can be controlled. Open the building up at night to ventilate and cool interior thermal mass. Close the buildings up during the daytime to keep the heat out. Therefore, with a standard passive solar system, dwellers feel more comfortable in terms of any conditions either cold weather or hot weather. It also has financial benefits. In fact, buildings require relatively small cooling or heating systems. (4)

Singh et.al (2016) research that the height to width ratio of the built mass with each other and other physical features like trees, streets etc. can help not only in desirable thermal indoor conditions but, can also reduce the use of valuable land for other purposes.(11)

According to design of $\mathbf{P} \mathbf{J}$ Trade Centre (2016) observed that the shading device, orientation, vegetation, natural ventilation, concrete vent blocks and material act as effective passive design that plays an important role in achieving thermal comfort. The garden plaza and trees planted around the building acts as filtration to cool the heated air. The uses of concrete vent blocks on parts of the building improve the space quality and enhance the ventilation for user's comfort. The concrete vent block also act as shading device that allows air to flow in thus making the building naturally ventilated. The natural ventilation and stack effect system used in PJ Trade Centre also help to enhance the ventilation system and fasten the time for the air to ventilate through the building. The orientation of the building helps support the design of the concrete vent block as natural cooling strategy. The brick material on the building also helps to absorb heat to achieve an average temperate of the surrounding for thermal comfort. (9)

\section{Conclusions}

After completion of its review, Following are the various major finding of the reviews.

1. Based on the design of the houses, it is expected that homes with low and near net-zero energy consumption can be designed in a cost effective manner within a period of about 5 years, provided a heat pump-based system is used for heating and heat is recovered from the PV system and efficiently utilized in the house. (3)

2. We may add passive solar elements like shading devices. Additional elements would keep the interior space at a more comfortable and stable temperature. Similarly, the indoor humidity can be controlled. (4)

3. Heat energy obtained from solar energy is stored by thermal mass floor which is used to maintain comfortable higher temperature inside the room in day time as well as in the night. The low cost materials used for the study in order to focus on low cost construction with comfortable result. (2) 
4. The energy-efficiency design strategies by passive solar components having the additional cost of about $9 \%$ of the total building cost, it is possible to save the total annual energy used in this specific residential building by $18 \%$. (1)

5. Advantages due to passive solar design like Energy performances, investment, attractive living environment, comfort, low maintenance, environmental concern. (15)

6. He compares the different method which we can use in passive solar energy building like direct gain, indirect gain, and isolated gain (5)

7. It is assumed that the buildings are in the northern hemisphere with most of the solar radiation coming from the south. (8)

8. The orientation, shading device, vegetation, concrete vent blocks, natural ventilation, and material act as effective passive design that plays an important role in achieving thermal comfort. The garden plaza and trees planted around the building acts as filtration to cool the heated air. The uses of concrete vent blocks on parts of the building improve the space quality and enhance the ventilation for user's comfort. The concrete vent block also act as shading device that allows air to flow in thus making the building naturally ventilated (9)

9. The present study looks at the relationship between the traditional buildings and sustainable development as well as the climatic conditions and construction patterns in Shiraz, Iran. (10)

10. Concept of documenting solar energy distribution through the use of a sun path diagram and the multiple ways in which this can be used for energy efficient buildings and also for evolving passive solutions possible in buildings and also provides an overview of the sun based passive solutions and design approaches possible in the case of buildings especially with reference to tropical countries. (4)

11. The height to width ratio of the built mass with each other and other physical features like trees, streets etc. can help not only in desirable thermal indoor conditions but, can also reduce the use of valuable land for other purposes. (11)

12. A small set of renewable energy technologies is considered-solar photovoltaic (PV), solarthermal electric generation, and wind electric power-with the results compared to the standard single-building assumption that $\mathrm{PV}$ is used to provide the on-site renewable generation. (13)

13. Solar design days as a useful method for understanding passive solar buildings' dynamic behavior for the purpose of increasing energy performance and gives a background on recent advances in passive solar design, a methodology for selecting and applying solar design days, and a modeling approach for passive solar houses in Energy. (14)

\section{ACKNOWLEDGMENT}

We want to thank Dr. Jayeshkumar Pitroda for his immense support and guidance in the accomplishment of our project. We would like to thanks him further for meeting with us every week and helping us solve all the doubts and providing detailed solutions. These helped us developed a lot of insights on passive solar system and gain conceptual knowledge during the span of this project. Dr. Jayeshkumar Pitroda was extremely helpful and generous throughout the project development.

\section{REFERENCES}

[1] Serkan BILGIC, “ A case study on improvement of an existing residential building's thermal performance by passive solar design" İzmir Institute of Technology İzmir, Turkey September, 2003

[2] Md. Tanbirujjaman, Md. Masudurrahman and A.N.M. MizanurRahman, "Design of a direct gain passive solar hetingsystem"proceedings of the 2010 international conference on industrial engineering and operational management Dhaka, Bangladesh, January 9-10 2010.

[3] Andreas anthienities "Design of advanced solar homes aimed at net zero annual energy consumption in canada" ISES-AP -3rd international solar energy society conference-Asia pacific region(ISES-AP-08)Incorporating the 46th ANZES conference 25-28 November 2008

[4] AbdolvahidKahoorzadeh, sahelshahvazari, elnazfarzami, sinaosivand "Investigation of Usage of Passive Solar Energy in Salamis Road's Buildings, Famagusta" International Journal of Environmental Science and Development, Vol. 5, No. 2, April 2014 
[5] Javedsadeghsaberi, sanazarei, shahab-o-din hemmati, Mohsen. Kameli,"passive solar building design” Journal of Novel Applied Sciences C2013 JNAS Journal-2013-2-S4/1178-1188 ISSN 2322-5149 (2013 JNAS

[6] B. Griffith, N. Long, P.Torcellini and R.Judkoff "Assessment of the technical potential for achieving net zero energy buildings in the commercial sector" Technical report NREL/TP-55041957 DEC 2007

[7] Karolisjanusevicius, Giedrestreckiene, violetamiseviciute,"Simulation and analysis of smallscale solar adsorption cooling system for cold climate" International journal of environmental science and development, vol-6, no-1, January 2015.

[8] Lentz, timothy Robert," Analysis of the passive design and solar collection techniques of the house in the 2009 U. S. Department of energy's solar decathol competition" Graduate theses and dissertations, paper 11361.

[9] Asian Architecture [ARC 2213/2234] "The Effectiveness of Passive Design Strategies as Natural Cooling Devices in Achieving Thermal Comfort at PJ Trade Centre.” Taylor's university(JUNE 2016)

[10] NajmehNajafi "Iranian Traditional Architecture And Energy Saving (Case Study: Shiraz Ghajar Houses)" International Journal Of Energy And Environment Volume 4, Issue 5, 2013 Pp.871878

[11] Ritu singh and madhurayadav "Study Of Energy Efficient Design Strategies For Building Clusters In Hot \& Dry Climate: An Overview " Emerging trends in Engineering \& Management for Sustainable Development 2016 International conference, Feb 2016

[12] Hoda shah nazari "Examining the potential for design and renewable energy to contribute to zero energy housing in queens land" School of chemistry, physics and mechanical engineering science and engineering faculty queens land university of technology 2014-BN72.

[13] Fernadez, N katipamula, S Brahmley, M. R. readdy, T.A. Economical investigation of community-scale versus building scale net zero energy.(12-2009)

[14] William O'Brien “Solar Design Days: A tool For Passive Solar House Design” NY-14-009 FEB 2014

[15] Subratochanndra and phillip w. fairey "passive solar design stratagies"

[16] David A. Bainbridge and Ken Haggard "Passive solar architecture" ISBN 9781603582964, published on July 2011.

[17] Bozen Bolzano "Building simulation applications BSA-2013" ISBN-9788860460585, Published on 2013 1ST Edition. 


\section{AUTHORS' BIOGRAPHY}

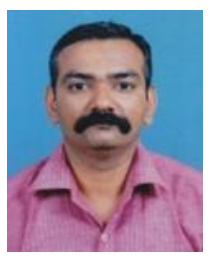

Dr. Jayeshkumar Pitroda, received his Bachelor of Engineering Degree in Civil Engineering from Birla Vishwakarma Mahavidyalaya Engineering College, Sardar Patel University in 2000. In 2009 he received his master's degree in Construction Engineering and Management form Birla Vishwakarma Mahavidyalaya Sardar Patel University. In 2015 he received his Doctor of Philosophy (Ph.D.) Degree in Civil Engineering from Sardar Patel University. He joined Birla Vishwakarma Mahavidyalaya Engineering College as a faculty in 2009, where he is Assistant Professor of Civil Engineering Department with a total experience of 16 years in the field of Research, Designing and Education. He is guiding M.E. / M.Tech (Construction Engineering and Management) thesis work in the field of Civil / Construction Engineering. He has published many papers in National / International Conferences and International Journals. He has published seven Research Books in the field of Civil Engineering, Rural Road Construction, National Highways Construction, Utilization of Industrial Waste, Fly Ash Bricks, Construction Engineering and Management, Eco-friendly Construction.

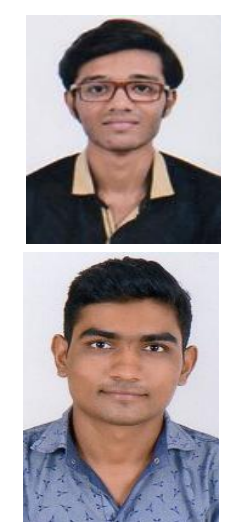

LalakiyaBirraj, was born in 1996 in UpletaCity.Atpresent, He is Final year student of Bachelor of Engineering in Civil from Birla Vishvakarma Mahavidyalaya, Gujarat Technological University.

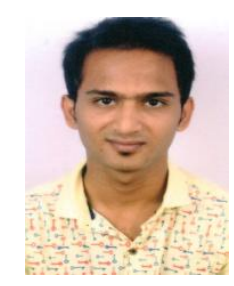

Naghera Dhiraj, was born in 1996 in RaypurCity, He is Final year student of Bachelor of Engineering in Civil from Birla Vishvakarma Mahavidyalaya, Gujarat Technological University.

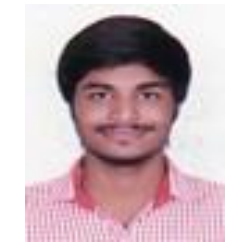

Patel Harsh, was born in 1996 in PatanCity, He is Final year student of Bachelor of Engineering in Civil from Birla Vishvakarma Mahavidyalaya, Gujarat Technological University. 